\title{
Diode Laser as an Adjunctive to Nonsurgical Periodontal Therapy during Maintenance Phase: A Randomized Controlled Clinical Trial
}

\author{
${ }^{1}$ SS Suprith, ${ }^{2}$ Swati Setty, ${ }^{3}$ Srinath Thakur
}

\begin{abstract}
Aim: The aim of the study was to determine and compare the pocket depths (PD), relative attachment levels (RAL), bleeding on probing $(\mathrm{BOP})$ and plaque indices $(\mathrm{PI})$ in patients treated with scaling and root planning (SRP) alone and along with diode laser.

Materials and methods: The study was carried out on 30 subjects who fulfill the inclusion and exclusion criteria. Group I: 15 patients treated with SRP along with diode laser irradiation. Group II: 15 patients treated only with SRP. The clinical parameters were probing $\mathrm{PD}, \mathrm{RAL}, \mathrm{BOP}$ and $\mathrm{PI}$ which were recorded at base line, 7 days and after 1 month. Statistical analysis was done using Kolmogorov-Smirnov, Shapiro-Wilk, t-test, chi-square test.
\end{abstract}

Results: The use of diode lasers as an adjunct to SRP during maintenance phase showed better results when compared to SRP alone. Moderate periodontal pockets with moderate attachment loss showed significant improvement in group I than in group II. There was no change in deep pockets with severe attachment loss in both groups.

Clinical significance: The study shows that the specified laser parameter and the modality of application of the same results in faster healing. This can be recommended as an appropriate treatment for moderate pockets.

Keywords: Dental laser, Laser dentistry, Laser dentistry treatments, Laser uses in dentistry.

How to cite this article: Suprit SS, Setty S, Thakur S. Diode Laser as an Adjunctive to Nonsurgical Periodontal Therapy during Maintenance Phase: A Randomized Controlled Clinical Trial. Int J Laser Dent 2016;6(1):12-17.

Source of support: Nil

Conflict of interest: None

\section{INTRODUCTION}

Periodontal therapy include of nonsurgical and surgical approaches as well as systematic follow-up care. ${ }^{1}$

${ }^{1}$ Postgraduate Student, ${ }^{2}$ Professor, ${ }^{3}$ Professor and Principal

${ }^{1-3}$ Department of Periodontics and Oral Implantology, Sri Dharmasthala Manjunatheshwara College of Dental Sciences and Hospital, Dharwad, Karnataka, India

Corresponding Author: SS Suprith, Postgraduate Student Department of Periodontics and Oral Implantology, Sri Dharmasthala Manjunatheshwara College of Dental Sciences and Hospital, Dharwad, Karnataka, India, Phone: +919538950366 e-mail: suprith90@gmail.com
Supportive therapy is very important within a periodontal treatment regimen and this has been shown in several studies. ${ }^{2,3}$ Oral hygiene reinforcement, scaling and root planing (SRP), polishing, chemical irrigation with antiseptic agents, local drug delivery with antibiotics like tetracycline fibers, low-level laser therapy (LLLT), photo dynamic therapy and other methods can be used for supportive periodontal therapy. Low-level laser therapy makes use of low-power lasers or light-emitting diodes (LEDs) for therapeutic uses. Among various physiological effects exerted by lasers, it is important to recognize that the biostimulatory effects, which low-level laser irradiation produces on cells of the tissue during laser therapy might be beneficial by allowing faster wound healing in the process of periodontal tissue repair, which may not occur during conventional mechanical therapy. ${ }^{4}$ Advantages of laser treatment when compared to conventional methods include low cellular loss and tissue inflammation, hemostasis, increased visualization of surgical sites, excellent tissue ablation, sterilization of the operating site, reduced pain after operating and patient acceptance. ${ }^{5,6}$

Low-level laser therapy has also been widely used as a part of the treatment of oral diseases in dentistry. Low-level laser therapy uses a light source that generates extremely pure light with a single wavelength. The effects that it can produce on the cell are due to photochemical reactions, rather than thermal effects, although the mechanisms behind this are still unclear. ${ }^{4}$ Laser is a promising alternative or adjunctive means of conventional and mechanical periodontal therapy.

Diode laser has a bactericidal detoxifying effects, but does not erode calculus on the root surface, therefore, it may be useful as a supportive means for SRP. ${ }^{7-13}$ Many studies have been reported the use of SRP + Laser but there are very few studies on lasers in maintenance phase. According to the best of author's knowledge, there are no reports evaluating the diode laser with the described parameters in our study during maintenance phase. This study was conducted to determine the effectiveness of diode laser as an adjunct to SRP during maintenance phase. 


\section{MATERIALS AND METHODS}

\section{Patient Selection and Study Design}

Patients were recruited from the Department of Periodontics and Oral Implantology, of the college and ethical clearance was obtained. The inclusion criterias were adult periodontal maintenance patient with a history of treatment for chronic periodontitis who had received no active or maintenance periodontal therapy at least 6-month prior to the study, systemically healthy subjects, subjects aged from 25 to 60 years, one or more periodontal sites with pocket depth $\geq 4 \mathrm{~mm}$, relative attachment level (RAL) $\geq 3 \mathrm{~mm}$, bleeding on probing (BOP) and subjects who were compliant with terms of study. Exclusion criterias were pregnant women and lactating mothers, smokers, use of antibiotics and analgesics within 6 months prior to study. This study was a randomized clinical trial. This trial has been registered in Clinical Trials Registry India and the CTRI number is CTRI/2016/06/007013.

Thirty five patients were assessed and five patients were not included to the study as three participants did not fulfil the selection criteria and two participants denied to participate in the study. Thirty patients were included in the study and completed the allocated periodontal therapy. The selected patients were assigned into any of the following two groups by coin toss method (Heads = Group I -15 patients and Tails = Group II - 15 patients). Periodontal pockets in each patient were divided into two subgroups according to baseline probing pocket depth (PD) and RAL: (1) Pocket depths of 4 to $6 \mathrm{~mm}$ (moderate pockets) and relative attachment loss of 7 to $9 \mathrm{~mm}$ (moderate loss) (2) pocket depths of $\geq 7$ (deep pockets) and relative attachment loss $\geq 10$ (severe loss). Patients were explained in detail about the nature and aim of the study and a signed written informed consent was obtained (Flow Chart 1).

\section{Clinical Parameters}

These clinical parameters were measured at baseline, 7th day and 1 month. Plaque index (PI) (Silness \& Loe 1964) was recorded at four sites around each tooth. Probing pocket depth was assessed by Michigan O probe with Williams markings on 4 surfaces of the teeth (mesiobuccal, buccal, distobuccal and palatal or lingual surfaces). It was measured from the gingival crest to the base of the pocket by using the occlusal level as a reference point.

Relative attachment level was measured using Michigan O probe with Williams markings. Here the term RAL indicates the measurement from the occlusal level as a fixed point to the base of the pocket and BOP as present

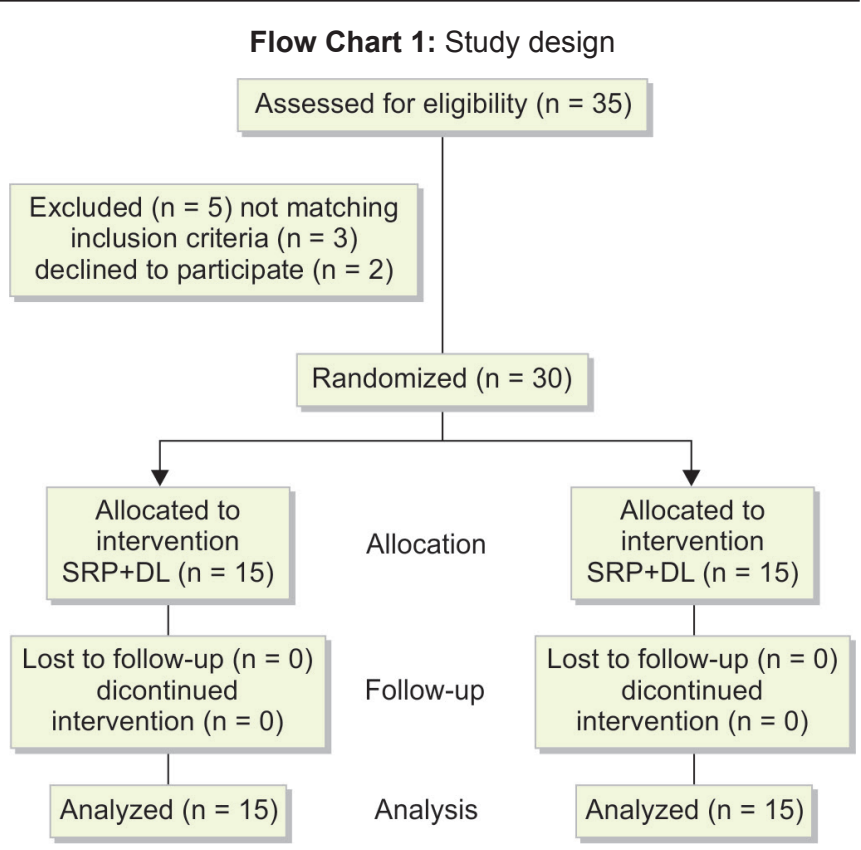

or absent. The parameters at all the time intervals were assessed by same investigator who was blinded regarding the type of treatment and the treatment as per randomization was performed by other operator. Hence, the outcome assessor was blinded.

\section{Treatment Protocol}

Thorough SRP using a piezoelectric ultrasonic unit (EMS) at a moderate setting and with the appropriate tips and curettes were also used where indicated and time spent in SRP on each tooth was not restricted and then only group I patients were treated with diode laser. All patients were given the oral hygiene instructions at baseline and reinforced in subsequent visits.

\section{Laser Treatment}

Gallium-aluminium-arsenide diode laser (ezlase ${ }^{\mathrm{TM}}$ ) with a wavelength of $940 \mathrm{~nm}$ set at a power output of $2 \mathrm{~W}$, average power $0.66 \mathrm{~W}$ in pulse interval of $20 \mathrm{~ms}$ and pulse length of $20 \mathrm{~ms}$ delivering $30 \mathrm{~s} / \mathrm{cm}^{2}$ and $15 \mathrm{~J} / \mathrm{cm}^{2}$ of energy was used. Irradiation was accomplished using a $300 \mu \mathrm{m}$ fiber optical delivery system which was moved from the coronal to the apical side of the interdental pockets. Lasing was performed from mesially to distally in buccal pockets and from distally to mesially in lingual/palatal pockets. Sweeping motion was used for every pocket in parallel paths with an inclination of approximately $20^{\circ}$ toward gingival wall reaching a total of 30 seconds for each tooth. Each pocket was lased for 30 second twice, with a 60 second interval at baseline and 7 days (Fig. 1). The fiber tip was regularly inspected and cleaned with damp sterile gauze to remove buildup of soft tissue debris on the tip during lasing. All the laser safety measures were followed. The periodontal pocket 


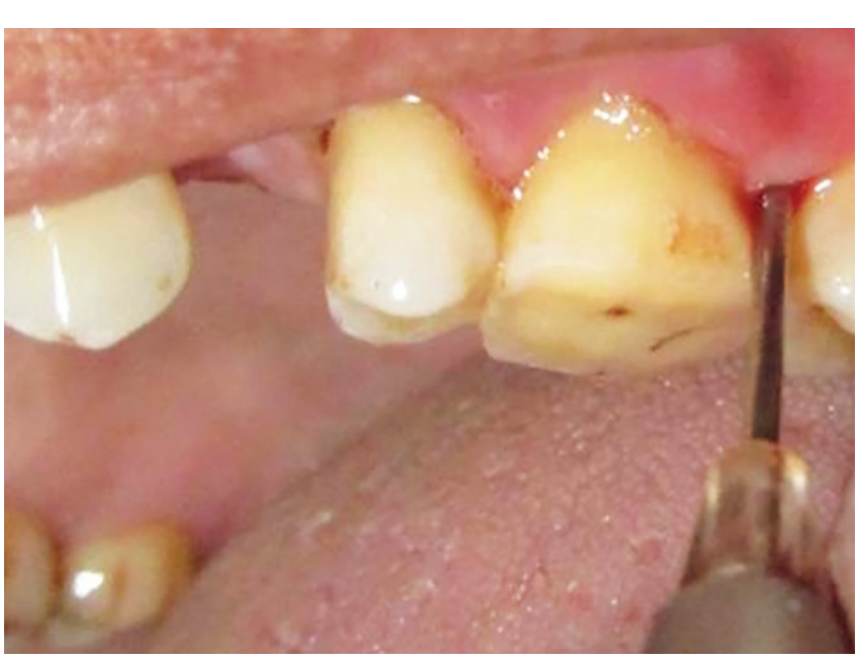

Fig. 1: Lazing

was irrigated with normal saline after each session of irradiation.

\section{Statistical Analysis}

All the results were documented in Microsoft Excel sheet and then the statistical analysis was done using Statistical Package for the Social Sciences version 11.0 software. Test of normality was done using KolmogorovSmirnov, Shapiro-Wilk, since most of the parameters were distributed normally. Parametric tests like independent and paired $t$ tests were used to analyse the data obtained. Pocket depth and RAL analysis was done by using chi-square test and $\mathrm{p}$-value $<0.05$ was considered significant.

\section{RESULTS}

In group I, comparison of PI and BOP showed significant reduction at all time periods. There was significant improvement in moderate PD from baseline to 30th day and 7th day to 30th day, and deep pockets did not show any statistical significant change. When RALs were compared with group t-test there was no significant difference, however, when paired t-test was used, it showed statistical significant difference from baseline to 7th day and from 7th day to 30th day for moderate RAL. And no statistical significant changes were observed in severe RAL.

In group II, comparison of PI and BOP showed significant reduction at all time periods except for the PI value between 7th day and 30th day. There was significant reduction in moderate PDs from baseline to 30th day and 7th day to 30th day but was not statistically significant. And deep pocket did not show any statistical significant difference. Relative attachment levels were compared with group t-test which showed no statistically significant difference for both moderate and severe RAL.

On comparing both the groups, PI showed statistically significant reduction in both the groups and BOP showed reduction in both the groups but at baseline and 7 th day the reduction was statistically significant in the group I (Table 1). Pocket depths were reduced in both groups when compared from baseline to day 30th, there was a statistically significant reduction in pocket depth in the group I when compared to group II on 30th day for moderate pocket, but was not so when compared on 7 th day for moderate pocket. Deep pocket $\geq 7 \mathrm{~mm}$ in both the treatment modalities showed no statistically significant reduction (Table 2). There was a statistically significant difference in RAL in group I when compared to group II at baseline and 7th day for moderate RAL but severe RAL did not show any statistically significant attachment gain (Table 3 ).

\section{DISCUSSION}

Clinical studies have shown that long-term clinical success of periodontal therapy is dependent on the continuing periodontal maintenance phase of therapy after active phase. ${ }^{14,15}$ During maintenance therapy, sites may

Table 1: Comparison of PI and BOP in groups I and II

\begin{tabular}{|c|c|c|c|c|c|c|}
\hline Time intervals & Groups & $n$ & Mean & Std. deviation & Std. error mean & $p$-value \\
\hline \multirow[t]{2}{*}{ Pl-base line } & I & 15 & 1.5127 & 0.43191 & 0.11152 & 0.102 \\
\hline & II & 15 & 1.7720 & 0.40835 & 0.10543 & \\
\hline \multirow[t]{2}{*}{ Pl-7th day } & I & 15 & 0.4307 & 0.18858 & 0.04869 & 0.102 \\
\hline & II & 15 & 0.3513 & 0.22335 & 0.05767 & \\
\hline \multirow[t]{2}{*}{ PI-30th day } & I & 15 & 0.5520 & 0.20692 & 0.05343 & 0.302 \\
\hline & II & 15 & 0.3353 & 0.30166 & 0.07789 & \\
\hline \multirow[t]{2}{*}{ BOP-base line } & I & 15 & 29.3333 & 11.05613 & 2.85468 & $0.030 *$ \\
\hline & II & 15 & 24.5333 & 10.76945 & 2.78066 & \\
\hline \multirow[t]{2}{*}{ BOP-7th day } & 1 & 15 & 14.4667 & 6.10464 & 1.57621 & $0.031^{*}$ \\
\hline & II & 15 & 13.0667 & 4.62086 & 1.19310 & \\
\hline \multirow[t]{2}{*}{ BOP-30th day } & I & 15 & 3.4000 & 3.01899 & 0.77950 & 0.238 \\
\hline & II & 15 & 2.4667 & 2.16685 & 0.55948 & \\
\hline
\end{tabular}

PI: Plaque index; BOP: Bleeding on probing ${ }^{*} p<0.05$ (Statistically significant) 
Diode Laser as an Adjunctive to Nonsurgical Periodontal Therapy during Maintenance Phase

\begin{tabular}{|c|c|c|c|c|c|}
\hline $\begin{array}{l}\text { Time } \\
\text { intervals }\end{array}$ & Groups & $\begin{array}{l}\text { No. of sites } \\
\text { with moderate } \\
\text { pocket } \\
4-6 \mathrm{~mm}\end{array}$ & $\begin{array}{l}\text { No. of } \\
\text { sites with } \\
\text { pocket } \\
\geq 7 \mathrm{~mm}\end{array}$ & $\begin{array}{l}\text { Chi- } \\
\text { square }\end{array}$ & $p$-value \\
\hline \multirow[t]{2}{*}{ Base line } & I & 240 & 26 & 0.042 & 0.837 \\
\hline & II & 226 & 26 & & \\
\hline \multirow[t]{2}{*}{ 7th day } & I & 240 & 26 & 0.002 & 0.964 \\
\hline & II & 226 & 26 & & \\
\hline \multirow[t]{2}{*}{ 30th day } & I & 50 & 26 & 11.759 & $0.001^{*}$ \\
\hline & II & 147 & 26 & & \\
\hline
\end{tabular}

have persistent disease which never resolved or may become reinfected, which requires further treatment. Lasers, photodynamic therapy, local drug delivery and others have been tried in maintenance therapy. Few studies have reported the use of various laser to treat reoccurring periodontal disease in periodontal maintenance patients. ${ }^{16-18}$ Diode laser-assisted periodontal therapy using photodynamic therapy was not superior to conventional mechanical debridement, ${ }^{19}$ however photodynamic therapy was shown to be superior in eliminating pockets especially in single rooted teeth maintenance phase as seen by Campos et al. ${ }^{20}$

In our study, piezoelectric ultrasonic unit (EMS) was used to perform SRP. Chapper et al found that there was no significant difference found in treatment outcomes of ultrasonic scaling alone or ultrasonic scaling followed by hand scaling as the final step. ${ }^{21}$ Ultrasonic scalers have been found to be effective in removing subgingival biofilm and calculus. It is known that endotoxins are loosely adsorbed on the root surface and its removal can be done using ultrasonic insert tips. ${ }^{22}$ However in our study, the use of curettes is done for complete and through removal of subgingival calculus.

In the present study, PI and BOP was reduced in both the groups which is in accordance with the previous studies ${ }^{11,23,24}$ except for PI in group II at day 7 th and 30th. More reduction of BOP in group I may be attributed to the reduction of periodontal inflammation and may also be related to the reduction of prostaglandin E2 (PGE2) levels, due to the effects of laser treatment. Prostaglandin E2 levels increase in the periodontal connective tissues of periodontal lesions being a potent stimulator of inflammation and bone resorption. ${ }^{25}$ A study done by Sakurai et al showed that low level laser irradiation may inhibit PGE2 production by lipopolysaccharide of periodontopathogens in human gingival fibroblast (hGF). The inhibitory effects on PGE2 production was time and dose dependent. ${ }^{26}$

Moderate pockets were reduced only in group I which was also found by various studies. ${ }^{12,13,16,17,23,27}$

We observed that this reduction was more so at 30th day and was not seen at 7th day which may be indicative of healing period of the treated pocket. ${ }^{28}$ The reduction in PD can be due to the availability of new site for the attachment of connective tissue. ${ }^{29}$ In cases of PDs, both the treatment modalities were not able to improve the condition. Ambrosini et $\mathrm{al}^{24}$ also did not observe any improvement in deep pockets. This may be due to incomplete elimination of microbial plaque. ${ }^{9}$

Group I showed statistically significant difference than group II on comparing moderate attachment loss at 7th day only, which may be due to greater retraction of periodontal tissues in the laser group and this achieved stability by 30 th day. ${ }^{28}$

In our study, diode laser led to significant improvement of clinical parameters (PD, RAL, BOP) after 30 days compared with that of SRP alone, Dukic ${ }^{13}$ also has similar results in maintenance phase. Other laser, such

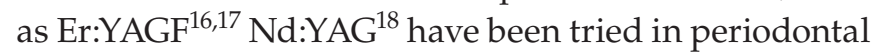
maintenance patients but they failed to show any additional benefits over conventional therapies. In our study, there may be other mechanism for the improved clinical response to laser therapy. Romanos et $\mathrm{al}^{30}$ showed that instrumentation of soft periodontal tissues with diode laser led to a complete epithelial elimination when compared to conventional treatment method with hand instruments. A study done by Kreisler et $\mathrm{al}^{29}$ stated that more reduction in PD might be due to the de-epithelization of the pockets leading to an enhanced connective tissue attachment. Laser therapy also increases the levels of vascular endothelial growth factor, transferring growth factor $\beta$ and mRNA expression of insulin growth factor on hGF resulting in a predominant role on the connective tissue metabolism, ${ }^{31}$ taking together it may be inferred that the laser leads to epithelial changes where epithelium modulates the connective tissue turnover during wound healing. ${ }^{32,33}$ So epithelial connective tissue interactions are important for periodontal structure homeostasis. Coagulation and blood clot stabilization is also shown by various studies. ${ }^{25,34}$ 
The beneficial effects of nonsurgical laser therapy to treat periodontal diseases have been discussed in many studies and reviews. ${ }^{35,36}$ These could be due to better subgingival debridement of the pocket and eradication of periodontal microorganism within the subgingival area. ${ }^{9}$ Diode lasers disinfect the bacteria thermally which is basically limited to the root surface. It was seen that Actinobacillus actinomycetemcomitans, Porphyromonas gingivalis, and Prevotella intermedia levels were reduced as long as 6 months. ${ }^{7}$

The reported results of use of diode lasers have been mixed. Some studies reported SRP $+\mathrm{L}$ better than SRP alone. ${ }^{10-12}$ In contrast to this, few studies found no additional effects of lasers. ${ }^{37,38}$ Meta-analysis/systematic reviews also showed no additional effect of laser. ${ }^{39,40}$ These changes in the results may be due to small sample size, difference in the definitions considered for classification of the disease, use of different laser system and its parameters. ${ }^{35}$

The results which evaluated parameters in few studies that used lasers of the same wavelength reported different results; which makes the analysis of results nearly impossible to compare and could be one of the reason for the conflicting evidence found in various clinical trials. ${ }^{35}$ Additional randomized controlled clinical trials are necessary to competently assess the efficacy of lasers used adjunctively to mechanical debridement especially in cases of severe periodontal destruction. Limitations of this study are the sample size used here is small and the patients needs to be further followed up for a longer time intervals.

\section{CONCLUSION}

Within the limitations of this study, the use of diode lasers as an adjunct to SRP during maintenance phase showed effective results when compared to SRP alone. Moderate periodontal pockets with moderate attachment loss showed significant improvement in laser group alone. There were no significant changes in deep pockets with severe attachment loss in both groups.

\section{CLINICAL SIGNIFICANCE}

The study showed that the specified laser parameter and the modality of application of the same results in faster healing. This can be recommended as an appropriate treatment for moderate pockets.

\section{REFERENCES}

1. Ratka-Kruger P, Mahl D, Deimling D, Mönting JS, Jachmann I, Al-Machot E, Sculean A, Berakdar M, Jervøe-Storm PM, Braun A. Er:YAG laser treatment in supportive periodontal therapy. J Clin Periodontol 2012 May;39(5):483-489.
2. Axelsson $\mathrm{P}$, Lindhe J. The significance of maintenance care in the treatment of periodontal disease. J Clin Periodontol 1981 Aug;8(4):281-294.

3. Lindhe J, Nyman S. Long-term maintenance of patients treated for advanced periodontal disease. J Clin Periodontol 1984 Sep;11(8):504-514.

4. Chung H, Dai T, Sharma SK, Huang YY, Carroll JD, Hamblin MR. The nuts and bolts of low-level laser (light) therapy. Ann Biomed Eng 2012 Feb;40(2):516-533.

5. Myers TD. Lasers in dentistry. J Am Dent Assoc 1991;122:46-50.

6. Raffetto N. Lasers for initial periodontal therapy. Dent Clin North Am 2004 Oct;48:923-936.

7. Moritz A, Schoop U, Goharkhay K, Schauer P, Doertbudak O, Wernisch J, Sperr W. Treatment of periodontal pockets with a diode laser. Lasers Surg Med 1998;22(5):302-311.

8. Harris DM, Yessik M. Therapeutic ratio quantifies laser antisepsis: ablation of Porphyromonas gingivalis with dental lasers. Lasers Surg Med 2004;35(3):206-213.

9. Moritz A, Gutknecht N, Doertbudak O, Goharkhay K, Schoop U, Schauer P, Sperr W. Bacterial reduction in periodontal pockets through irradiation with a diode laser: A pilot study. J Clin Laser Med Surg 1997 Feb;15:33-37.

10. Üstün K, Erciyas K, Sezer U, enyurt SZ, Gündoğar $H$, Üstün Ö, Öztuzcu S. Clinical and biochemical effects of $810 \mathrm{~nm}$ diode laser as an adjunct to periodontal therapy: a randomized split-mouth clinical trial. Photomed Laser Surg 2014 Feb;32(2):61-66.

11. Saglam M, Kantarci A, Dundar N, Hakki SS. Clinical and biochemical effects of diode laser as an adjunct to nonsurgical treatment of chronic periodontitis: a randomized, controlled clinical trial. Lasers Med Sci 2014 Jan; 29(1):37-46.

12. Kamma JJ, Vasdekis VG, Romanos GE. The effect of diode laser $(980 \mathrm{~nm}$ ) treatment on aggressive periodontitis: evaluation of microbial and clinical parameters. Photomed Laser Surg 2009 Feb;27(1):11-19.

13. Dukić W, Bago I, Aurer A, Roguljić M. Clinical effectiveness of diode laser therapy as an adjunct to non-surgical periodontal treatment: a randomized clinical study. J Periodontol 2013 Aug;84(8):1111-1117.

14. Wilson TG Jr, Glover ME, Malik AK, Schoen JA, Dorsett D. Tooth loss in maintenance patients in a private periodontal practice. J Periodontol 1987 Apr;58(4):231-235.

15. Becker W, Becker BE, Berg LE. Periodontal treatment without maintenance. A retrospective study in 44 patients. J Periodontol 1984 Sept;55(9):505-509.

16. Tomasi C, Schander K, Dahlén G, Wennström JL. Short-term clinical and microbiologic effects of pocket debridement with an Er:YAG laser during periodontal maintenance. J Periodontol 2006 Jan;77(1):111-118.

17. Krohn-Dale I, Bøe OE, Enersen M, Leknes KN. Er:YAG laser in the treatment of periodontal sites with recurring chronic inflammation: a 12-month randomized, controlled clinical trial. J Clin Periodontol 2012 Aug;39(8):745-752.

18. Slot DE, Timmerman MF, Versteeg PA, van der Velden U, van der Weijden FA. Adjunctive clinical effect of a watercooled Nd:YAG laser in a periodontal maintenance care programme: a randomized controlled trial. J Clin Periodontol 2012 Dec;39(12):1159-1165.

19. Rühling A, Fanghänel J, Houshmand M, Kuhr A, Meisel P, Schwahn C, Kocher T. Photodynamic therapy of persistent pockets in maintenance patients-a clinical study. Clin Oral Investig 2010 Dec;14(6):637-644. 
20. Campos GN, Pimentel SP, Ribeiro FV, Casarin RC, Cirano FR, Saraceni $\mathrm{CH}$, Casati MZ. The adjunctive effect of photodynamic therapy for residual pockets in single-rooted teeth: a randomized controlled clinical trial. Lasers Med Sci 2013 Jan;28(1):317-324.

21. Chapper A, Catão VV, Oppermann RV. Hand and ultrasonic instrumentation in the treatment of chronic periodontitis after supragingival plaque control. Braz Oral Res 2005 JanMar;19(1):41-46.

22. Smart GJ, Wilson M, Davies EH, Kieser JB. The assessment of ultrasonic root surface debridement by determination of residual endotoxin levels. J Clin Periodontol 1990 Mar;17(3):174-178.

23. Caruso U, Nastri L, Piccolomini R, d'Ercole S, Mazza C, Guida L. Use of diode laser $980 \mathrm{~nm}$ as adjunctive therapy in the treatment of chronic periodontitis. A randomized controlled clinical trial. New Microbiol 2008 Oct;31(4):513-518.

24. Ambrosini P, Miller N, Briançon S S, Gallina S, Penaud J. Clinical and microbiological evaluation of the effectiveness of the Nd:Yap laser for the initial treatment of adult periodontitis. A randomized controlled study. J Clin Periodontol 2005 Jan;32(6):670-676.

25. Offenbacher S, Odle BM, Van Dyke TE. The use of crevicular fluid prostaglandin E2 levels as a predictor of periodontal attachment loss. J Periodontal Res 1986 Mar;21(2):101-112.

26. Sakurai Y, Yamaguchi M, Abiko Y. Inhibitory effect of lowlevel laser effect irradiation on LPS-stimulated prostaglandin E2 production and cyclooxygenase-2 in human gingival fibroblasts. Eur J Oral Sci 2000 Feb;108(1):29-34.

27. Aykol G, Baser U, Maden I, Kazak Z, Onan U, TanrikuluKucuk S, Ademoglu E, Issever H, Yalcin F. The effect of lowlevel laser therapy as an adjunct to non-surgical periodontal treatment. J Periodontol 2011 Mar;82(3):481-488.

28. Cobb CM. Non-surgical pocket therapy: mechanical. Ann Periodontol 1996 Nov;1(1):443-490.

29. Kreisler M, Al Haj H, d'Hoedt B. Clinical efficacy of semiconductor laser application as an adjunct to conventional scaling and root planing. Lasers Surg Med 2005 Dec;37(5):350-355.

30. Romanos GE, Henze M, Banihashemi S, Parsanejad HR, Winckler J, Nentwig GH. Removal of epithelium in periodontal pockets following diode $(980 \mathrm{~nm})$ laser application in the animal model: an in vitro study. Photomed Laser Surg 2004 Jun;22(3):177-183.
31. Hakki SS, Bozkurt SB. Effects of different setting of diode laser on the mRNA expression of growth factors and type I collagen of human gingival fibroblasts. Lasers Med Sci 2012 Mar;27(2):325-331.

32. Sume SS, Kantarci A, Lee A, Hasturk H, Trackman PC. Epithelial to mesenchymal transition in gingival overgrowth. Am J Pathol 2010 Jul;177(1):208-218.

33. Kantarci A, Nseir Z, Kim YS, Sume SS, Trackman PC. Loss of basement membrane integrity in human gingival overgrowth. J Dent Res 2011 Jul;90(7):887-893.

34. Sohi Rastegar; Steven L. Jacques; Massoud Motamedi and Beop-Min Kim. "Theoretical analysis of equivalency of highpower diode laser $(810 \mathrm{~nm})$ and Nd:YAG laser $(1064 \mathrm{~nm})$ for coagulation of tissue: predictions for prostate coagulation", Proc. SPIE 1646, Laser-Tissue Interaction III, 150 (August 7, 1992); doi:10.1117/12.137454; Available from: http://dx.doi. org $/ 10.1117 / 12.137454$

35. Cobb CM. Lasers in periodontics: a review of the literature. J Periodontol 2006 Apr;77(4):545-564.

36. Slot DE, Kranendonk AA, Paraskevas S, Van der Weijden F. The effect of a pulsed Nd:YAG laser in non-surgical periodontal therapy. J Periodontol 2009 Jul;80(7):1041-1056.

37. Nguyen NT, Byarlay MR, Reinhardt RA, Marx DB, Meinberg TA, Kaldahl WB. Adjunctive non-surgical therapy of inflamed periodontal pockets during maintenance therapy using diode laser: a randomized clinical trial. J Periodontol 2015 Oct;86(10):1133-1140.

38. Balasubramaniam AS, Thomas LJ, Ramakrishnanan T, Ambalavanan N. Short-term effects of nonsurgical periodontal treatment with and without use of diode laser $(980 \mathrm{~nm})$ on serum levels of reactive oxygen metabolites and clinical periodontal parameters in patients with chronic periodontitis: a randomized controlled trial. Quintessence Int 2014 Mar;45(3):193-201.

39. Sgolastra F, Severino M, Gatto R, Monaco A. Effectiveness of diode laser as adjunctive therapy to scaling root planing in the treatment of chronic periodontitis: a meta-analysis. Laser Med Sci 2013 Sep;28(5):1393-1402.

40. Slot DE, Jorritsma KH, Cobb CM, Van der Weijden FA. The effect of the thermal diode laser (wavelength 808-980 nm) in non-surgical periodontal therapy: a systematic review and meta-analysis. J Clin Periodontol 2014 Jul;41(7):681-692. 